\title{
Mobile Connectivity and Adolescent Well-being. Evidence from a Randomised Control Trial on a Media Education Training Programme in High Schools
}

\author{
Marco Gui ${ }^{*}$, Tiziano Gerosa ${ }^{\mathrm{a}}$, Gianluca Argentin ${ }^{\mathrm{a}}$, Lucilla Losi ${ }^{\mathrm{b}}$ \\ ${ }^{a}$ Department of Sociology and Social Research, University of Milano-Bicocca, Milano, Italy \\ ${ }^{\mathrm{b}}$ Department of Political Science, University of Aarhus, Aarhus, Denmark \\ * Corresponding author \\ E-mail: marco.gui@unimib.it
}

\begin{abstract}
In recent years a growing public debate has started on smartphone use by young people. Research has found adverse relationships between smartphone intensive use and well-being. However, there has been a lack of structured interventions targeting schools and families. This paper shows the results of a cluster randomised controlled trial evaluating the impact of a media education intervention focusing on time management and the conscious use of mobile devices. The impact of a teachers' training course is assessed on their 10th-grade students, looking at their smartphone use, online content management, and subjective well-being. Treated students show a significant decrease in problematic smartphone use, with girls showing impacts also on their content-mediated digital skill and a beneficial effect on general well-being. We discuss how such evidence may contribute to the scholarly debate about the well-being consequences of problematic smartphone use and to the development of effective policies in the field.
\end{abstract}

Keywords: problematic smartphone use, digital skills, digital well-being, high school, media education, cluster randomised controlled trial, teacher training, youth and digital media. 


\section{Mobile Connectivity and Adolescent Well-being. Evidence from a Randomised Control \\ Trial on a Media Education Training Programme in High Schools}

\section{Introduction}

The relationship between adolescents and smartphones is often at the core of public debate. In recent years, thanks in particular to the spread of mobile media, screen time has increased for every age range, but especially for children and adolescents (Ofcom, 2020). Thanks to their smartphones, many teenagers are online on a near-constant basis (Pew Research Center, 2018). Concerns have grown among families and educational institutions about the possible adverse health and developmental effects of pervasive digital practices (Blum-Ross \& Livingstone, 2016).

Apart from a small minority of pathologically "addicted" young users (Kim et al. 2014; Merlo et al., 2013; Kwon et al., 2013), less severe but more widespread problematic implications of smartphone usage on youth have emerged in the scientific literature. Research has found negative associations between smartphone use and outcomes such as concentration (Kushlev et al., 2016), sleep quality (Christensen et al., 2016), satisfaction with body perception (Schmuck et al., 2019), quality of interpersonal relationships (Mahapatra, 2019) and school performance (Samaha \& Hawi, 2016). A number of studies have also found a negative association between intensive smartphone use and life satisfaction (e.g. Twenge et al. 2020; Rotondi et al., 2017; Vahedi \& Saiphoo, 2018). A causal interpretation of these associations is not straightforward and has been questioned (Orben \& Przybylski, 2020), also because reverse causality seems to be plausible (Kim et al., 2019a; Kula et al., 2020). However, both longitudinal studies (Liu et al., 2020) and controlled trials (Throuvala et al. 2020) have reinforced the idea that a more conscious management of smartphone usage can be beneficial 
to young people. It is to be noted that in this field of research sharp gender differences emerge, with girls spending more time on smartphones and being more at risk of problematic use (Demirci et al., 2015; Extremera et al., 2019; Lin \& Chiang, 2017).

There is agreement that schools should target the issue of well-being in permanently online environments (Yu \& Shek, 2013; Eurydice, 2019). However, the educational system seems unprepared to respond to such a challenge. So far, schools have mostly dealt (and struggled) with new media as teaching tools, introducing educational technologies in classrooms to foster knowledge within the disciplines (Selwyn, 2016). Instead, when it comes to education on a conscious use of digital media, schools have largely lacked a structured approach (Buckingham, 2013, 2019). Not only are few experiences of education on constant connection emerging (e.g. Themelis \& Sime, 2020), it must also be emphasised that none has been rigorously assessed. Hence, we do not know whether media education interventions may be effective in reducing problematic use and, if the above causal relationship exists, in improving adolescents' well-being.

In the present study, we introduce and evaluate a media education intervention targeting young people through their schools which combines the two dimensions of digital well-being in mobile environments outlined above: time and attention management in daily life and online content management. The intervention is aimed at promoting a conscious, strategic, and responsible use of mobile media and, ultimately, at enhancing digital well-being. The "Digital Well-being - Schools" programme was developed by an interdisciplinary group of experts in media education and well-being in adolescence. Then the programme was administered to teachers of 41 classes at grade 10 in northern Italy. We assess the impact of such a programme on students through a cluster randomised trial, looking at variations in smartphone time management skills and perceived problematic use, online information and relationship management skills, capital-enhancing digital media use and subjective well-being over one 
academic year. Overall, our study contributes to two strands of emerging literature: we provide evidence about the potential effectiveness of interventions on mobile media use and, by manipulating it, we test the causal impact of mobile connection on adolescents' well-being. Moreover, we exploit gender differences along both dimensions, since previous research has shown this variable plays a crucial role in this field.

In the following, after a literature review (paragraph 2), description of the intervention (paragraph 3), and methodological features of our experimental study (paragraph 4), we present the results (paragraph 5) and discuss the implications both for digital well-being theory and the development of future policies (paragraph 6).

\section{Literature review: the issue of adolescents' problematic smartphone use}

According to a recent report by EU Kids Online, 80\% of children aged 9-16 in EU countries have daily access to the internet through a smartphone, a growing trend since 2010 (Smahel et al., 2020). A survey of US youth found that $45 \%$ of teenagers say they are almost constantly online through mobile media (Pew Research Center, 2018). The most common daily activities that children and adolescents carry out on smartphones are participating in social networks, chatting online, watching videos, and playing online games (Graafland, 2018; Kumar \& Radcliffe, 2019; Smahel al., 2020).

Due to this particularly pervasive use of screens, youth has been the focus of theoretical contributions about so-called "digital well-being" (Nansen et al., 2012; Gui et al., 2017; Burr et al., 2020). In its general meaning, this label refers to a "state where subjective well-being is maintained in an environment characterised by digital communication overabundance" (Gui et al., 2017; 166). Such overabundance emerges as the cumulative effect of the internet, social media, and mobile devices (Chayko, 2017). The challenge brought by permanent mobile connectivity to digital well-being among youth is two-fold, according to the literature: on the 
one hand, a great deal of scholarly attention has been focused on time and attention management, given that permanent connection is characterised by task switching, the ubiquity of work and leisure activities (Ofcom, 2016; Gerosa et al. 2021). On the other hand, some of the more "traditional digital skills" such as online information and relationship management become even more key in a permanent connectivity environment (Büchi, 2020; Abeele et al., 2018).

In the following paragraphs, we review the literature concerning these two domains in the specific case of smartphone usage.

\subsection{Time and attention management}

The constant presence of smartphones multiplies our possibilities for communicating, socialising, and being informed. However, their multiple, appealing, and ubiquitous content can also present a problem in that they challenge users' ability to manage time and attention allocation in daily life (Ofcom, 2016; Rainie \& Zickuhr, 2015).

Regarding adolescents, smartphone pervasiveness has been analysed particularly in relation to specific daily activities that are socio-physiologically fundamental for the general well-being of children and youth: sleeping, social interaction, and school-related activities. Many adolescents have access to a smartphone when in their bedroom (Graafland, 2018), and research has shown that prolonged exposure to this device can interfere with the sleep cycle and sleep quality (Christensen et al., 2016; Hughes and Burke, 2018). Media-related sleep deprivation can also be related to the insurgence of depressive symptoms in the long run (Lemola et al., 2015).

As for social interaction, online relations appear to be complementary to offline friendships (Chan, 2018), but constant mediated contact is associated with a lower quality of offline social experiences (Bae, 2015; Kim et al. 2018). Indeed, in an experiment about the quality of human 
relations in the presence or absence of a smartphone in the visual field, lower levels of empathy, closeness, and depth of conversation were observed when a phone was present (Przybylski \& Weinstein, 2013). Longer periods spent online on a smartphone are also associated with more offline family conflicts (Kim et al., 2019b).

Finally, intensive smartphone use, during daytime and night-time, appears to interfere with school-related activities by affecting students' ability to concentrate (Kushlev et al., 2016; Seo et al., 2016). In particular, using a smartphone while performing other tasks is common among young users (Graafland, 2018), but research has shown that being used to constantly switching tasks has negative repercussions on individuals' attention and cognitive performance (Ophir et al., 2009). Furthermore, concentration difficulties and frequent use of smartphones are linked to a smaller amount of efficient time dedicated to studying (Junco \& Cotten, 2011) and ultimately to poorer school performance (Liu et al., 2020).

Research also shows that such smartphone-related flipsides are widely perceived by young people as problematic (Rodríguez-Gómez et al., 2018).

\subsection{Online content management}

What makes the use of smartphones problematic is not just the quantity and pervasiveness of their use, but also a lack of awareness and strategic thought in their use.

First, it is important to consider that problematic smartphone use has been found to be associated in particular with the passive use of social networking sites (SNSs) (Panek et al. 2018; Elhai et al., 2019; Rozgonjuk et al., 2019; Karsay et al., 2019). Furthermore, research has consistently shown that the passive use of social media (e.g., monitoring other users' profiles, pictures, and posts) is linked to lower subjective well-being (Liu et al., 2019). Indeed, passive use of SNSs enhances upward social comparison and negative self-perception with negative consequences on well-being (Lee, 2014; Kleemans et al., 2018; Schmuck et al., 2019), 
especially for those who have a lower level of self-esteem (Ahadzadeh et al., 2017). Conversely, interactive social media usage (e.g. direct communication, self-disclosure, broadcasting, and publication of self-produced content) positively associates with subjective well-being (Wang et al., 2014), also in longitudinal (Wenninger et al., 2019) and experimental research (Verduyn et al., 2015).

Among the correlates of smartphone intensive use, there is also considerable scholarly focus on one-to-one communication, often through the use of text messaging. Research suggests that intensive mobile phone use in close relationships has contradictory consequences: it increases expectations of maintaining the relationship but it also increases feelings of entrapment, guilt, and pressure to respond (Hall \& Baym, 2012). Compared with face-to-face interaction or phone calls, text communications are more likely to give rise to misinterpretation and difficult communication (Johnson et al., 2016; Kelly et al., 2012). Moreover, chatting with others who are not physically present often takes place when other activities are being carried out, lowering the level of attention with negative impacts on relational quality (Kelly \& Miller-Ott, 2018).

In addition, information consumption can become particularly problematic in a permanent connectivity setting where stimuli are abundant and always available (Stephens et al., 2017). In an experimental study with college students, Panek (2014) found that selecting from a large number of websites increases the probability of choosing immediately gratifying options, such as social media. While task switching, in general, seems to deplete self-regulatory resources (Hamilton et al., 2011; Rubinstein et al., 2001), this is also the case in media consumption (Gui et al., 2021). In particular, Kazakova et al. (2015) showed that media multitasking decreases critical evaluation of the persuasive message, as users rely on heuristic and automatic processing. A conscious approach to information consumption in a constant connectivity regimen is, therefore, key to mobile digital well-being. 


\subsection{The crucial role played by gender}

The literature has systematically found a gender difference in the way smartphone use and related consequences manifest themselves. In general, girls spend more time on smartphones and seem to be more at risk of problematic use and addiction than boys (Demirci et al., 2015; Kwon et al., 2013; Extremera et al., 2019; Lin \& Chiang, 2017; Kim et al. 2019). Some studies report that female users are more prone to use their smartphone before going to bed and for longer intervals (Li et al., 2015; Lemola et al., 2015). The reason for this might be that the social use of the device, which seems to be more time-consuming, is more frequent among girls (Lee et al., 2016). Indeed, the two genders differ in their media habits: boys seem to be more prone to playing online games whereas girls are more attracted by social networking platforms and online chats (Lee \& Chae, 2007; Lee et al., 2016; Graafland, 2018).

Also, social media use - in particular exposure to photos and images portrayed in these environments - seems to associate with more negative indicators for female adolescents compared with their male counterparts (Blomfield \& Barber, 2014; Meier \& Gray, 2014; Rodgers et al. 2020).

Finally, a stronger association between general digital media use and lower well-being has been observed for females (Przybylski and Weinstein, 2017; 2019).

\section{The Digital Well-being - Schools intervention and its expected impacts}

In the light of the evidence presented, challenges to the digital well-being of youth in the mobile era come from specific problems in terms of:

1) time and attention management in daily life related to the use of mobile devices;

2) online content management concerning cognitive and social capital-enhancing use.

Therefore, we expect an intervention designed to increase skills and awareness around these two domains to reduce problems in the daily management of smartphones and content-related 
issues. If the association between mobile media use and well-being is causal, we should find also a positive impact of our intervention on adolescents' well-being. In addition, we should find greater impacts of our intervention on females, they being more exposed to the negative consequences of permanent connectivity.

\subsection{Intervention features}

A group of experts in different disciplines was assembled in the form of a steering committee, with the goal of designing a detailed protocol for an intervention that could exploit the expected dynamics shown above. ${ }^{1}$ As noted by the committee, there is agreement in the literature that schools should educate to a balanced and conscious use of digital media, including everyday usage outside of schools (Kwon, 2011; Yu \& Shek, 2013; Euridyce, 2019). However, research in this field mainly focuses on computer use and is aimed at tackling general health behaviour (e.g. Busch et al., 2013), reducing internet overuse (e.g. Turel et al., 2015) and addictive gaming habits (de Leeuw et al., 2010; Walther et al., 2014). Moreover, this branch of interventions has rarely invested in the direct involvement of teachers (Walther et al., 2014), being in most cases administered by external experts (Busch et al., 2013; de Leeuw et al., 2010; Turel et al., 2015). Instead, the involvement of teachers, who are part of the learning environment of the treated students, is recommended in order to achieve a significant impact in terms of behavioural and cognitive change in school-based media education projects (Vondráčková \& Gabrihelik, 2016).

Therefore, the committee decided on a training package that addressed teachers and invited them to perform targeted media education activities with their students (Gui et al., 2018). The Digital Well-being - School project attempts to overcome traditional approaches based on spot interventions led by external experts, providing teachers with the "toolbox" needed to discuss

\footnotetext{
${ }^{1}$ For further details about the composition of the steering committee, see (Gui et al., 2018)
} 
the critical issues of digital technology autonomously. The course was designed to be administered in a blended environment and was divided into four training modules: Time and Attention Management, Communication and Collaboration, Information Evaluation and Digital Content Production.

Each module was structured in a first stage of online preparatory work followed by inperson training with media educators focused on basic concepts and lesson planning, providing teachers with the theoretical basis and actual lesson plans to deliver a three-hour "media awareness experience" in their classroom. At the end of each experience, teachers were invited to cooperate with students in defining a "good digital habit" to be consolidated inside and outside of school (with family, friends, etc.) for the rest of the year. Good habits were the legacy of each module's experience, adding up over the course of the year and ultimately providing students with four good digital habits. The habits were devised by the research team to extend and reinforce the impact of the media experiences well beyond the 12-hour classroom project. For this reason, teachers of the classes involved were invited to regularly refer to the habits during their class time throughout the year.

In the first module, which focused on time and attention management, students were invited to download a monitoring app to keep track of their smartphone-related activities. Research shows that monitoring apps can help increase digital self-awareness, although their use should be accompanied by thinking about self-imposed goals to modify habits (Rooksby et al., 2016; Zimmermann, 2020). For this reason, one week later, students were guided by teachers in developing an "Attention Management Plan" based on this activity report, to identify forms of self-regulation in media use and set some time management goals. The activity also involved students' families.

The other three modules covered the most relevant activities that are performed using mobile media, using the digital skills dimensions drawn up by the European Digital Competence 
Framework for Citizens (DigComp 2.1): peer-communication, information management, and digital content production. Module 2 addressed the management of online relationships and conflicts, examining real-life examples from mobile instant messaging applications and social media. The experience consisted in the collective creation of a class group netiquette. Module 3 covered the topic of searching for information using specific techniques, checking the validity of sources, and knowledge management. An online search on a specific topic was then proposed to the class, asking students to put the results in order of reliability and to give reasons why they opted for a specific order. The collated criteria were finally included in general guidelines for the class. Module 4 concerned responsible online content production, publication, promotion, and sharing. Students were asked to create in groups a simple product (a "meme") with their devices to be published online. In doing this, they were asked to follow a simple checklist for designing digital products responsibly and consciously. Referring to the checklist every time something digital was produced from then on represented the final good habit of the module ${ }^{2}$. The collective outcome of each module was finally summarized in a poster that was hung in the classroom.

\subsection{Expected impacts}

All things considered, we expect the Digital Well-being - School intervention to have the following specific impacts. First, we hypothesise that - compared with control students - treated students will report a greater increase in teachers' support in digital media use over the year, as the result of the effective implementation of the media education activities in the classes (H0). Based on the activities of module 1, we hypothesise that students exposed to the contents of the intervention will acquire the necessary skills to significantly reduce smartphone pervasiveness during key social and physiological moments of their daily life (H1a), thus

\footnotetext{
${ }^{2}$ For more details on the module contents, see Gui et al. (2018).
} 
experiencing a reduction in smartphone disturbance of their adaptive functions and perceived risks of smartphone-related withdrawal symptoms (H1b). We also expect that students' participation in the activities of modules 2, 3 and 4 will increase their overall ability to manage online information, relationships and content in a context of intensive connectivity (e.g. selecting and evaluating online information, managing online relationships, and responsibly producing, promoting and sharing online content $(\mathrm{H} 2 \mathrm{a})$. Based on this expected result, we also hypothesise that students involved in the project will effectively exploit this renewed set of content-related skills to make more use of online capital-enhancing strategies aimed at increasing their cognitive and social opportunities (H2b).

We also expect to find an overall positive effect of the intervention on students' subjective well-being, as a causal consequence of its expected reduction of smartphone problematic use and improvement of online capital-enhancing activities (H3).

Finally, in the light of the divide that emerged in the literature between male and female problematic smartphone use, we expect the intervention to reduce pre-existing gender gaps in terms of smartphone pervasiveness and problematic use (H4a), thus indirectly contributing to a more consistent growth in girls' general well-being compared with that of their male counterparts (H4b).

\section{Experimental design}

The impact of the Digital Well-being - School intervention was assessed at the student level, using a cluster trial, pre-registered in the Social Science Registry. ${ }^{3}$ Randomised trials are rapidly gaining attention in the evaluation of education interventions, including in Italy (a country lacking attention towards evidence-based policies) (Argentin, 2019), being a powerful tool for developing rigorous causal inference.

\footnotetext{
${ }^{3}$ https://www.socialscienceregistry.org/trials/2990
} 


\subsection{School recruitment}

An invitation to take part in the project was sent to all 42 high schools in three administrative districts in the North of Italy. A multiple-stage enrolment procedure was implemented to ensure that school principals and teachers were all properly informed about the project structure, contents, aims, and requirements, to avoid their subsequent dropping out during the experiment. The project budgeted for the allocation of about 80 teachers $(2$ teachers per class) to the intervention, for a total coverage of about 40 classes (around 820 students). Using power calculation, we estimated that the total number of comparison classes to be involved in the trial was 130 (around 2,600 students), in order to detect effects on primary outcomes of around 0.100 in terms of effect size. We then recruited the first 18 schools that signed our cooperation agreement respecting the distribution of the different school types located in the districts being studied, for a total of $17110^{\text {th }}$ grade classes and their 3,659 enrolled students.

\subsection{Randomisation}

In October 2017, all the $10^{\text {th }}$-grade classes of the 18 high schools were randomly allocated to an intervention group (40 classes) or a comparison group (131 classes).

Randomisation was carried out at class level using a random allocation sequence based on sequentially numbered containers. Some of the recruited schools offered only one Course of Study (COS) at the time of the intervention, while others had two or more COS. In the overall sample, the classes were organised into five main COS: lyceum (scientific area); lyceum (other areas); technical school (economic area); technical school (technological area); vocational school. Our constraints were: a. guaranteeing the direct involvement of all the schools in the first year of intervention, and $b$. at the same time, ensuring an equal distribution of the $10^{\text {th }}$ grade classes from each of the above-mentioned COS between treated and control groups. We 
opted for a randomisation approach based on blocks of classes defined by COS. A total of 31 intra-school blocks (based on classes with the same COS within each school) were identified and, in addition, another two inter-school blocks were created to cover also those COS that counted only one class within a specific school. Randomisation was carried out within each of the 33 blocks, randomly assigning to the treatment one class if the block contained six or fewer classes and assigning to the treatment two classes if the block was made up of seven or more classes.

\subsection{Intervention implementation}

Each class assigned to the treatment identified and named two teachers to take part in the training initiative during its first delivery. ${ }^{4}$ To both encourage greater exposure of students to the training content and reduce the likelihood of teachers working in more than one 10th grade class being trained (namely to reduce the risk of contamination), it was requested that the sum of the total hours per week spent by the selected teachers on the individual class assigned to the treatment would be equal or greater than seven.

The four training modules of the intervention were then provided to all the selected teachers of the randomly selected classes between December 2017 and April 2018, at variable time intervals depending on the school calendar. After each training meeting, teachers were requested to develop and carry out a related media education activity only with students of the treated classes, without implementing it in the other classes, and were asked not to share it with other colleagues from the training group.

\footnotetext{
4 Teachers of the comparison group were instead assigned to a waiting list and asked to attend the training the following school year (AY 2018-2019). We planned an additional training session for the comparison group after the end of the trial to provide access to the intervention to all the teachers and students initially excluded from the treatment. The idea behind that was to prevent ethical concerns and scepticism toward the project, ensuring compliance with the principle of equality in educational opportunities.
} 


\subsection{Data collection}

In November 2017, before being informed that they would be participating in the project as a treatment or control group, students from all the recruited classes were asked to take a digital competence test and to fill in a questionnaire on their socio-demographic characteristics, uses, perceptions and attitudes towards new media and their well-being. The data were collected in the multimedia laboratories of the schools using a CAWI methodology (Computer Assisted Web Interviewing), during the school day and under the supervision of external observers appointed and trained by the research group (who were not aware of the classes' experimental condition).

The second wave of data collection was conducted on all students after the end of the intervention, in May 2018 (once treated teachers had completed all the media education activities). On this occasion, students were asked to retake the digital knowledge test and fill in the questionnaire again, using the same method and procedures adopted in the first wave. It is important to underline that also in this case students were not informed about their experimental condition and could not connect the assessment to the intervention, the questionnaires having been presented to them as part of a different academic research process without any reference to the Digital Well-being - School project.

Figure 1, in the usual form of a flow diagram, shows the trial design and figures for enrolment, randomisation, follow-up, and analyses.

\section{[Figure 1]}

\subsection{Outcomes}

All the outcomes in the study were measured before and after the intervention at student level - both in the treatment and control group - and normalised to a 0-100 scale. Here we 
briefly report the key feature of each outcome, while the supplementary materials offer a more detailed description of their contents and statistical properties (SM1).

Perceived teacher support. Teachers' support in the use of digital media was measured through a battery of seven dichotomous items asking students whether they felt they had received specific forms of help from their teachers since the beginning of the school year. The items were designed ad hoc to measure students' exposure to the media education activities carried out by teachers in each of the training modules.

Smartphone pervasiveness. Smartphone pervasiveness in students' daily life was measured using the Smartphone Pervasiveness Scale for Adolescents (SPS-A) (Gerosa et al., 2021). The SPS-A consists of a battery of seven items asking respondents how frequently they use their devices at various times of the day that could be negatively affected by excessive smartphone use (e.g. at dinner with family, while studying).

Problematic smartphone use. Perceived smartphone problematic use was measured by extracting the two sub-dimensions of disturbance of adaptive functions and withdrawal from the Smartphone Addiction Scale - short version for adolescents (Kwon et al. 2013) and the Smartphone Addiction Proneness Scale (Kim et al. 2014). Disturbance of adaptive functions focuses on five items measuring the perceived negative consequences of smartphone use on respondents' ability to get along in their social environment with the most success and least conflict with others (e.g., my school grades dropped due to excessive smartphone use, people around me tell me that I use the smartphone too much). Withdrawal was instead defined by five items on perceived difficulties in managing abstinence from using a smartphone (e.g., I feel impatient and fretful when I am not holding my smartphone).

Digital competence test. Students' digital competence was measured through a standardised test composed of 32 multiple-choice items based on realistic stimuli and situations that young people may encounter when using a smartphone or other devices connected to the 
web (Gui et al., 2018). This test focuses on quantifying the level of awareness respondents have in searching for, using and producing information, in communicating, and in safely handling their online experience and identity (Van Deursen \& Van Dijk, 2014).

Capital-enhancing Internet and digital media use. By capital-enhancing use we mean ways of using media based on strategies able to increase the social and cognitive opportunities of users (Hargittai \& Hinnant, 2008). In this study, we included three measures of capitalenhancing activities, respectively focused on the use of the internet for information purposes, the creative use of digital media, and the interactive (as opposed to passive) use of social media. Based on previous research on tangible outcomes of internet use (Helsper et al. 2015) we focused on four items, asking students to report whether their use of the web effectively contributed to an increase in their knowledge of specific topics, to forming opinions on specific issues and to learning new things about different cultures. The index of creative use is instead composed of three items measuring the frequency with which respondents engage in the creation and sharing of original digital content (Ekström \& Östman 2015). Finally, the interactive use index focuses on four items aimed at measuring how often they publish content or interact with other users on social media (Escobar-Viera et al. 2018).

General well-being. General well-being was measured with the original version of the satisfaction with life scale (Diener et al. 1985), which focuses of five items for the selfassessment of overall life satisfaction and is well suited for use also with adolescents.

\subsection{Statistical analyses}

The internal validity of the experiment was first evaluated examining the cross-group equivalence of the distribution of a rich set of covariates measured before the intervention at both the individual and the class level. We also estimated a series of t-tests on all the baseline outcomes to compare their average scores across treated and control groups. Compliance and 
(differential) attrition - the two main threats to randomised trials' interval validity - were also investigated, looking at teachers' effective participation in the training initiative and at variations in students' survey response rates. Finally, the issue of contamination was also investigated by comparing average variations in students' perception of teacher support over time across the experimental groups. The results of these analyses, showing the absence of biases for our randomised trial, are provided in the supplementary materials (SM2).

The impact of Digital Well-being - School on the selected outcomes was estimated using an intention-to-treat approach (ITT), suitable in our case thanks to low participant noncompliance/dropout (Hollis \& Campbell, 1999). The ITT models were estimated at student level using ordinary least square (OLS) regression models, introducing randomisation blocks and baseline values of each outcome as covariates and clustering coefficient standard errors at class level, as normally the case in experimental studies (Hayes \& Moulton, 2017). All impacts are reported in terms of their raw regression coefficient and Cohen's D effect sizes, in order to maximise magnitude comparability (Cohen, 1988).

Regarding impact heterogeneity on gender bases, we replicated our models, introducing an interaction term between treatment and student gender in OLS regressions.

\section{Results}

Table 1 shows the results of the Digital Well-being - School impact evaluation at student level. Here we report the average predicted scores for both treated and control groups at the end of the intervention, the main effects of the intervention, and their respective effect sizes.

The first column of the table focuses on perceived teacher support in the use of digital media, as a proxy of students' effective exposure to the training contents. Our analysis confirmed that treated students perceived a significant increase in teachers' support compared with the control group $(\beta=26.5, p<.001)$, resulting in the rather large effect size of the intervention $(E S=$ 
0.873). This relevant gain in teachers' support can be read as a first proof of the effective implementation of the training experience in the class, thus confirming $\mathrm{H} 0$.

Moving onto the impact of the intervention on smartphone time management, we found a moderate but significant reduction in the frequency of smartphone use during relevant daily moments on treated students $(\beta=-2.6, p=0.001, E S=-0.183)$. As such, we confirm our expectations around H1a. In line with this result, we also found a significant decrease in mobile media-related disturbances of treated students' adaptive functions $(\beta=-2.0, p=0.006, E S=-$ 0.117), while no relevant evidence emerges concerning smartphone withdrawal. Based on these results, we can partially confirm our expectations around the effectiveness of the intervention in reducing the negative consequences of pervasive smartphone use (H1b).

\section{[Table 1]}

With regard to the second set of hypotheses, we hypothesised that students' participation in such media education activities could contribute to an increase in their overall ability to manage online information, relationships, and content in a context of intensive connectivity (H2a). Moreover, we expected treated students to adopt online capital-enhancing strategies aimed at increasing their social and cognitive opportunities more often (H2b). Our analyses show the absence of any relevant consequence of the intervention on these outcomes, thus suggesting that both hypotheses should be rejected.

Similarly, the third set of hypotheses is also not confirmed: treated students' overall satisfaction with life did not vary significantly compared with the control group. We can therefore also reject $\mathrm{H} 3$ on the indirect effect of the intervention on students' general wellbeing. 
The subsequent set of adjusted OLS ITT models, the results of which are reported in table 2, introduced an additional interaction term between treatment and students' gender in order to study the differential impacts of the intervention among males and females.

\section{[Table 2]}

Although we did not find relevant variations in perceived teachers' support - meaning that we can reasonably exclude gender-based differences in the effective exposition or sensitivity towards the media education activities carried out by teachers - girls reported a higher reduction in smartphone pervasiveness compared with their male counterparts (females: $\beta=-3.2, p=0.001, E S=-0.195$; males: $\beta=-2.0, p=0.078, E S=-0.170)$. Based on these results, we can confirm both $\mathrm{H} 3 \mathrm{a}$ and $\mathrm{H} 3 \mathrm{~b}$. Differential effects are also found in the area of digital competence, with girls slightly improving their final performance in the standardised test $(\beta=1.0, p=0.038, E S=0.045)$. However, this result should be interpreted with caution in the light of its moderate effect size. Finally, we registered a small but significant gender-based variation in the impact of the intervention on students' overall satisfaction with life, with girls reporting an average increase over the year $(\beta=1.8, p=0.021, E S=0.123)$ compared with the statistically non-significant decrease experienced by males. Therefore, we can also give empirical confirmation to $\mathrm{H} 4 \mathrm{a}$ and $\mathrm{H} 4 \mathrm{~b}$.

It is interesting to note that the differential effects we found are not only explainable by looking at previous literature on gender-based divides in smartphone problematic use, but also appear to be due to significant pre-intervention differences among male and female students in the outcomes of interest (as displayed in table 3).

\section{[Table 3]}


More precisely, we observed that females appeared to be more exposed than males to smartphone pervasiveness $(\Delta M=2.6, p<.001)$ before the intervention, perceived higher disturbance of adaptive functions $(\Delta M=3.0, p<.001)$ and, most of all, reported higher levels of smartphone withdrawal $(\Delta M=8.0, p<.001)$ and lower satisfaction with life $(\Delta M=5.9, p<$ $.001)$.

\section{Discussion and conclusions}

In this paper, we have described the motivation, theory, methodological design, and results of a cluster randomised trial assessing the impact of a media education intervention on youth smartphone usage habits and online content management, evaluating its consequential causal impact on adolescents' well-being. The logic behind the intervention was to provide students with "media awareness experiences", followed by the establishment of good habits to be developed and referred to throughout the academic year.

The programme was implemented as expected and the experiment's validity was preserved. As expected, treated students reported increased teacher support in the use of digital media at the end of the year, a significant decrease in smartphone pervasiveness in their daily lives and in its negative consequences on adaptive functioning. At the same time, but in this case unexpectedly, the intervention was not effective in increasing students' online content management skills. and we also did not get any impact on a ctive and creative digital media use or on tangible outcomes of internet use. Also the consequential impact on students' wellbeing after mobile use manipulation did not emerge in the overall sample.

Interestingly, and in line with baseline data and previous literature on young females' higher exposure to mobile over-use, treated girls show higher benefits on indicators relating to time and attention management, digital competence and also on their general well-being. 
In terms of the substantive interpretation of these results, the intervention impacted more on reducing smartphone problematic use in its time management dimension rather than on bettering online content management. A possible interpretation is that the effects of the training course on time management and smartphone pervasiveness were able to manifest themselves in a one-year time frame, while those on digital competence need more time to emerge. This is in line with the literature on behavioural change that shows habits can be modified in a relatively short time (Lally et al., 2010), while learning digital skills is a longer and more complex process (Van Deursen \& Van Dijk, 2014).

Overall, our results lead to the conclusion that improving time and attention management with mobile media is a promising area of work for media education interventions of this type and duration. In particular, as time and attention management are emerging in the public debate as core challenges within a constant connectivity environment, the activities proposed in module 1 can be important components of short-time media education interventions for young people.

Regarding the interpretation of gender differences, females not only appeared to be more prone to problematic smartphone use before the intervention, they also show greater and significant benefits to their digital competence and general well-being. These results are noteworthy in that interventions such as ours seem able to reduce gender gaps in problematic smartphone use that have emerged in the literature in recent years.

Despite its limitation to girls, the impact of the intervention on subjective well-being is worthy of separate discussion. Indeed, this piece of evidence is particularly relevant because it establishes a causal path connecting (reduced) problematic smartphone use to (improved) wellbeing, helping to shed light on an important but still widely debated issue in the literature. Based on our experience and given the relevance of problematic smartphone use among young people, we strongly believe that teacher training as the kind presented here should be included 
in school curricula and other educational institutions. It must be underlined that reflections and experiences like those proposed in our training programme can be integrated into daily teaching of all subjects, making schools autonomous in the delivery of digital media education with the potential for scaling up.

This study has two main limitations. The first concerns the level of social desirability affecting self-reported measures of mobile use among adolescents, despite our care to blind the data collection process and disconnect it from the intervention. Future research should invest more in the integration of traditional survey instruments, adding objective indicators of smartphone frequency and type of use to questionnaires. A second limitation, typical of randomised trials, is the lack of external validity of our results. As stated in the paper, descriptive statistics about our sample, its size and variability make us confident that we were not intervening in a highly unusual context; nonetheless, replication of the trial in other schools and national settings would appear crucial to learn more about interventions in this emerging field.

Finally, future research should also better disentangle the specific mechanisms by which digital well-being can be increased through mobile media education in a constant connectivity environment.

\section{References}

Abeele, M. V., De Wolf, R., \& Ling, R. (2018). Mobile media and social space: How anytime, anyplace connectivity structures everyday life. Media and Communication, 6(2), 5-14.

Ahadzadeh, A. S., Sharif, S. P., \& Ong, F. S. (2017). Self-schema and self-discrepancy mediate the influence of Instagram usage on body image satisfaction among youth. Computers in Human Behavior, 68, 8-16.

Argentin, G. (2019). Gli esperimenti nelle scienze sociali: molta strada resta da fare per un 
dibattito maturo sul tema. Quaderni di Sociologia, 81(81-LXIII), 131-141.

Bae, S. M. (2015). The relationships between perceived parenting style, learning motivation, friendship satisfaction, and the addictive use of smartphones with elementary school students of South Korea: Using multivariate latent growth modeling. School Psychology International, 36(5), 513-531.

Blomfield Neira, C. J., \& Barber, B. L. (2014). Social networking site use: Linked to adolescents' social self-concept, self-esteem, and depressed mood. Australian Journal of Psychology, 66(1), 56-64.

Blum-Ross, A., \& Livingstone, S. (2016). Families and screen time: Current advice and emerging research.

Büchi, M. (2020). A Proto-theory of Digital Well-being.

Buckingham, D. (2013). Media education: Literacy, learning and contemporary culture. John Wiley \& Sons.

Buckingham, D. (2019). The media education manifesto. John Wiley \& Sons.

Busch, V., De Leeuw, R. J., \& Schrijvers, A. J. (2013). Results of a multibehavioral healthpromoting school pilot intervention in a Dutch secondary school. Journal of Adolescent Health, 52(4), 400-406.

Burr, C., Taddeo, M., \& Floridi, L. (2020). The ethics of digital well-being: A thematic review. Science and engineering ethics, 1-31.

Chan, M. (2018). Mobile-mediated multimodal communications, relationship quality and subjective well-being: An analysis of smartphone use from a life course perspective. Computers in Human Behavior, 87, 254-262.

Chayko, M. (2017). Superconnected: The Internet, Digital Media, and Techno-Social Life. SAGE Publications.

Christensen, M. A., Bettencourt, L., Kaye, L., Moturu, S. T., Nguyen, K. T., Olgin, J. E., ... \& 
Marcus, G. M. (2016). Direct measurements of smartphone screen-time: relationships with demographics and sleep. PloS one, 11(11), e0165331.

Cohen, J. (1988). Statistical Power Analysis for the Behavioral Sciences. Hillsdle.

De Leeuw, J. R. J., de Bruijn, M., de Weert-van Oene, G. H., \& Schrijvers, A. J. (2010).

Internet and game behaviour at a secondary school and a newly developed health promotion programme: a prospective study. BMC public health, 10(1), 544.

Demirci, K., Akgönül, M., \& Akpinar, A. (2015). Relationship of smartphone use severity with sleep quality, depression, and anxiety in university students. Journal of behavioral addictions, 4(2), 85-92.

Diener, E. D., Emmons, R. A., Larsen, R. J., \& Griffin, S. (1985). The satisfaction with life scale. Journal of personality assessment, 49(1), 71-75.

Ekström, M., \& Östman, J. (2015). Information, interaction, and creative production: The effects of three forms of internet use on youth democratic engagement. Communication Research, 42(6), 796-818.

Elhai, J. D., Rozgonjuk, D., Alghraibeh, A. M., \& Yang, H. (2019). Disrupted daily activities from interruptive smartphone notifications: Relations with depression and anxiety severity and the mediating role of boredom proneness. Social Science Computer Review, 0894439319858008.

Escobar-Viera, C. G., Shensa, A., Bowman, N. D., Sidani, J. E., Knight, J., James, A. E., \& Primack, B. A. (2018). Passive and active social media use and depressive symptoms among United States adults. Cyberpsychology, Behavior, and Social Networking, 21(7), 437-443.

Eurydice (2019), Digital education at school in Europe. Available at: https://eacea.ec.europa.eu/national-policies/eurydice/content/digital-education-schooleurope en 
Extremera, N., Quintana-Orts, C., Sánchez-Álvarez, N., \& Rey, L. (2019). The Role of Cognitive Emotion Regulation Strategies on Problematic Smartphone Use: Comparison between Problematic and Non-Problematic Adolescent Users. International journal of environmental research and public health, 16(17), 3142.

Graafland, J. H. (2018). New technologies and 21st century children: Recent trends and outcomes.

Gerosa, T., Gui, M., \& Büchi, M. (2020). Smartphone Use and Academic Performance: A Pervasiveness Approach Beyond Addiction. Social Science Computer Review, Advance online publication, 08944393211018969.

Gui, M., Fasoli, M., \& Carradore, R. (2017). “Digital well-being”. Developing a new theoretical tool for media literacy research. Italian Journal of Sociology of Education, 9(1), 155-173.

Gui, M., Gerosa, T., Garavaglia, A., Petti, L., \& Fasoli, M. (2018). Digital well-being. Validation of a digital media education programme in high schools. Report, Research Center on Quality of Life in the Digital Society, University of Milano-Bicocca, Italy, November.

Gui, M., Shanahan, J., \& Tsay-Vogel, M. (2021). Theorizing inconsistent media selection in the digital environment. The Information Society, 1-23.

Hall, J. A., \& Baym, N. K. (2012). Calling and texting (too much): Mobile maintenance expectations,(over) dependence, entrapment, and friendship satisfaction. New media \& society, 14(2), 316-331.

Hamilton, R., Vohs, K. D., Sellier, A. L., \& Meyvis, T. (2011). Being of two minds: Switching mindsets exhausts self-regulatory resources. Organizational Behavior and Human Decision Processes, 115(1), 13-24.

Hargittai, E., \& Hinnant, A. (2008). Digital inequality: Differences in young adults' use of the 
Internet. Communication research, 35(5), 602-621.

Hayes, R. J., \& Moulton, L. H. (2017). Cluster randomised trials. CRC press.

Helsper, E. J., Van Deursen, A. J., \& Eynon, R. (2015). Tangible outcomes of Internet use: from digital skills to tangible outcomes project report.

Hollis, S., \& Campbell, F. (1999). What is meant by intention to treat analysis? Survey of published randomised controlled trials. Bmj, 319(7211), 670-674.

Hughes, N., \& Burke, J. (2018). Sleeping with the frenemy: How restricting 'bedroom use'of smartphones impacts happiness and wellbeing. Computers in Human Behavior, 85, 236244.

Johnson, A. J., Bostwick, E., Anderson, C., Gilchrist-Petty, E. S., \& Long, S. D. (2016). How do computer-mediated channels negatively impact existing interpersonal relationships. Contexts of the dark side of communication, 241-252.

Junco, R., \& Cotten, S. R. (2011). Perceived academic effects of instant messaging use. Computers \& Education, 56(2), 370-378.

Karsay, K., Schmuck, D., Matthes, J., \& Stevic, A. (2019). Longitudinal effects of excessive smartphone use on stress and loneliness: the moderating role of self-disclosure. Cyberpsychology, Behavior, and Social Networking, 22(11), 706-713.

Kazakova, S., Cauberghe, V., Pandelaere, M., \& De Pelsmacker, P. (2015). Can't see the forest for the trees? The effect of media multitasking on cognitive processing style. Media psychology, 18(4), 425-450.

Kelly, L., Keaten, J. A., Becker, B., Cole, J., Littleford, L., \& Rothe, B. (2012). "It's the American lifestyle!": An investigation of text messaging by college students. Qualitative Research Reports in Communication, 13(1), 1-9.

Kelly, L., \& Miller-Ott, A. E. (2018). Perceived miscommunication in friends' and romantic partners' texted conversations. Southern Communication Journal, 83(4), 267-280. 
Kim, S. G., Park, J., Kim, H. T., Pan, Z., Lee, Y., \& McIntyre, R. S. (2019a). The relationship between smartphone addiction and symptoms of depression, anxiety, and attentiondeficit/hyperactivity in South Korean adolescents. Annals of general psychiatry, 18(1), 1.

Kim, D., Lee, Y., Lee, J., Nam, J. K., \& Chung, Y. (2014). Development of Korean smartphone addiction proneness scale for youth. PloS one, 9(5), e97920. https://doi.org/10.1371/journal.pone.0097920

Kim, H. J., Min, J. Y., Min, K. B., Lee, T. J., \& Yoo, S. (2018). Relationship among family environment, self-control, friendship quality, and adolescents' smartphone addiction in South Korea: Findings from nationwide data. PloS one, 13(2), e0190896.

Kim, M. H., Min, S., Ahn, J. S., An, C., \& Lee, J. (2019b). Association between high adolescent smartphone use and academic impairment, conflicts with family members or friends, and suicide attempts. PloS one, 14(7), e0219831.

Kleemans, M., Daalmans, S., Carbaat, I., \& Anschütz, D. (2018). Picture perfect: The direct effect of manipulated Instagram photos on body image in adolescent girls. Media Psychology, 21(1), 93-110.

Kumar, D. K., \& Radcliffe, P. (2019). How and Why Students Use Smartphones. In Teaching Surrounded by Smart Phones (pp. 7-26). Springer, Singapore.

Kula, H., Ayhan, C., Kaçay, Z., \& Soyer, F. (2020). The Relationship between Smartphone Addiction and Life Satisfaction: Faculty of Sport Sciences Students. International Journal of Psychology and Educational Studies, 7(1), 86-95.

Kushlev, K., Proulx, J., \& Dunn, E. W. (2016). " Silence Your Phones" Smartphone Notifications Increase Inattention and Hyperactivity Symptoms. In Proceedings of the 2016 CHI conference on human factors in computing systems (pp. 1011-1020).

Kwon, M., Lee, J. Y., Won, W. Y., Park, J. W., Min, J. A., Hahn, C., ... \& Kim, D. J. (2013). 
Development and validation of a smartphone addiction scale (SAS). PloS one, 8(2), e56936.

Lally, P., Van Jaarsveld, C. H., Potts, H. W., \& Wardle, J. (2010). How are habits formed: Modelling habit formation in the real world. European journal of social psychology, 40(6), 998-1009.

Lee, S. J., \& Chae, Y. G. (2007). Children's Internet use in a family context: Influence on family relationships and parental mediation. Cyberpsychology \& behavior, 10(5), 640644

Lee, S. Y. (2014). How do people compare themselves with others on social network sites?: The case of Facebook. Computers in Human Behavior, 32, 253-260.

Lee, K. E., Kim, S. H., Ha, T. Y., Yoo, Y. M., Han, J. J., Jung, J. H., \& Jang, J. Y. (2016). Dependency on smartphone use and its association with anxiety in Korea. Public Health Reports, 131(3), 411-419.

Lemola, S., Perkinson-Gloor, N., Brand, S., Dewald-Kaufmann, J. F., \& Grob, A. (2015). Adolescents' electronic media use at night, sleep disturbance, and depressive symptoms in the smartphone age. Journal of youth and adolescence, 44(2), 405-418.

Li, J., Lepp, A., \& Barkley, J. E. (2015). Locus of control and cell phone use: Implications for sleep quality, academic performance, and subjective well-being. Computers in Human Behavior, 52, 450-457.

Lin, T. T., \& Chiang, Y. H. (2017). Investigating predictors of smartphone dependency symptoms and effects on academic performance, improper phone use and perceived sociability. International Journal of Mobile Communications, 15(6), 655-676.

Liu, D., Baumeister, R. F., Yang, C. C., \& Hu, B. (2019). Digital communication media use and psychological well-being: A meta-analysis. Journal of Computer-Mediated Communication, 24(5), 259-273. 
Liu, X., Luo, Y., Liu, Z. Z., Yang, Y., Liu, J., \& Jia, C. X. (2020). Prolonged Mobile Phone Use Is Associated with Poor Academic Performance in Adolescents. Cyberpsychology, Behavior, and Social Networking, 23(5), 303-311.

Mahapatra, S. (2019). Smartphone addiction and associated consequences: Role of loneliness and self-regulation. Behaviour \& Information Technology, 38(8), 833-844.

Meier, E. P., \& Gray, J. (2014). Facebook photo activity associated with body image disturbance in adolescent girls. Cyberpsychology, Behavior, and Social Networking, 17(4), 199-206.

Merlo, L. J., Stone, A. M., \& Bibbey, A. (2013). Measuring problematic mobile phone use: development and preliminary psychometric properties of the PUMP scale. Journal of addiction, 2013.

Nansen, B., Chakraborty, K., Gibbs, L., MacDougall, C., \& Vetere, F. (2012). Children and Digital Wellbeing in Australia: Online regulation, conduct and competence. Journal of Children and Media, 6(2), 237-254.

Ofcom (2020), Children and parents: Media use and attitudes report. London: Ofcom. Retrieved from: https://www.ofcom.org.uk/research-and-data/media-literacyresearch/childrens/childrens-media-lives

Ofcom. (2016) The Communications Market Report 2016. . Retrieved from: https://www.ofcom.org.uk/research-and-data/multi-sector-research/cmr/cmr16

Orben, A., \& Przybylski, A. K. (2020). Reply to: Underestimating digital media harm. Nature Human Behaviour, 4(4), 349-351.

Ophir, E., Nass, C., \& Wagner, A. D. (2009). Cognitive control in media multitaskers. Proceedings of the National Academy of Sciences, 106(37), 15583-15587.

Panek, E. (2014). Evidence for the effects of parental mediation and childhood media use on US college students' social media use. Journal of Children and Media, 8(2), 127-145. 
Panek, E., Khang, H., Liu, Y., \& Chae, Y. G. (2018). Profiles of problematic smartphone users: A comparison of South Korean and US college students. Korea Observer, 49(3), 437464.

Pew Research Center (2018), Teens, Social Media \& Technology 2018, URL https://www.pewresearch.org/internet/wpcontent/uploads/sites/9/2018/05/PI_2018.05.3 1_TeensTech_FINAL.pdf

Przybylski, A. K., \& Weinstein, N. (2013). Can you connect with me now? How the presence of mobile communication technology influences face-to-face conversation quality. Journal of Social and Personal Relationships, 30(3), 237-246.

Przybylski, A. K., \& Weinstein, N. (2017). A large-scale test of the goldilocks hypothesis: quantifying the relations between digital-screen use and the mental well-being of adolescents. Psychological Science, 28(2), 204-215.

Przybylski, A. K., \& Weinstein, N. (2019). Digital Screen Time Limits and Young Children's Psychological Well-Being: Evidence From a Population-Based Study. Child Development, 90(1), e56-e65.

Rainie, L., \& Zickuhr, K. (2015). “Americans' Views on Mobile Etiquette.” Pew Research Center. Available at: http://www.pewinternet.org/2015/08/26/americans-views-onmobile-etiquette/

Rodgers, R. F., Slater, A., Gordon, C. S., McLean, S. A., Jarman, H. K., \& Paxton, S. J. (2020). A biopsychosocial model of social media use and body image concerns, disordered eating, and muscle-building behaviors among adolescent girls and boys. Journal of youth and adolescence, 49(2), 399-409.

Rodriguez-Gomez, D., Castro, D., \& Meneses, J. (2018). Problematic uses of ICTs among young people in their personal and school life. Comunicar. Media Education Research Journal, 26(2). 
Rooksby, J., Asadzadeh, P., Rost, M., Morrison, A., \& Chalmers, M. (2016). Personal tracking of screen time on digital devices. In Proceedings of the 2016 CHI conference on human factors in computing systems (pp. 284-296).

Rotondi, V., Stanca, L., \& Tomasuolo, M. (2017). Connecting alone: Smartphone use, quality of social interactions and well-being. Journal of Economic Psychology, 63, 17-26.

Rozgonjuk, D., Elhai, J. D., Täht, K., Vassil, K., Levine, J. C., \& Asmundson, G. J. (2019). Non-social smartphone use mediates the relationship between intolerance of uncertainty and problematic smartphone use: Evidence from a repeated-measures study. Computers in Human Behavior, 96, 56-62.

Rubinstein, J. S., Meyer, D. E., \& Evans, J. E. (2001). Executive control of cognitive processes in task switching. Journal of experimental psychology: human perception and performance, 27(4), 763.

Samaha, M., \& Hawi, N. S. (2016). Relationships among smartphone addiction, stress, academic performance, and satisfaction with life. Computers in human behavior, 57, 321-325.

Schmuck, D., Karsay, K., Matthes, J., \& Stevic, A. (2019). "Looking Up and Feeling Down”. The influence of mobile social networking site use on upward social comparison, selfesteem, and well-being of adult smartphone users. Telematics and Informatics, 42, 101240.

Selwyn, N. (2016). Education and technology: Key issues and debates. Bloomsbury Publishing.

Seo, D. G., Park, Y., Kim, M. K., \& Park, J. (2016). Mobile phone dependency and its impacts on adolescents' social and academic behaviors. Computers in human behavior, 63, 282292.

Smahel, D., MacHackova, H., Mascheroni, G., Dedkova, L., Staksrud, E., Olafsson, K., ... \& 
Hasebrink, U. (2020). EU Kids Online 2020: Survey results from 19 countries.

Stephens, K. K., Mandhana, D. M., Kim, J. J., Li, X., Glowacki, E. M., \& Cruz, I. (2017). Reconceptualizing communication overload and building a theoretical foundation. Communication Theory, 27(3), 269-289.

Themelis, C., \& Sime, J. A. (2020). Mapping the field of digital wellbeing education: A compendium of innovative practices and open educational resources.

Throuvala, M. A., Griffiths, M. D., Rennoldson, M., \& Kuss, D. J. (2020). Mind over matter: Testing the efficacy of an online randomized controlled trial to reduce distraction from smartphone use. International journal of environmental research and public health, 17(13), 4842.

Turel, O., Mouttapa, M., \& Donato, E. (2015). Preventing problematic Internet use through video-based interventions: A theoretical model and empirical test. Behaviour \& Information Technology, 34(4), 349-362.

Twenge, J. M., Haidt, J., Joiner, T. E., \& Campbell, W. K. (2020). Underestimating digital media harm. Nature Human Behaviour, 4(4), 346-348.

Vahedi, Z., \& Saiphoo, A. (2018). The association between smartphone use, stress, and anxiety: A meta-analytic review. Stress and Health, 34(3), 347-358.

Van Deursen, A. J., \& Van Dijk, J. A. (2014). Digital skills: Unlocking the information society. Springer.

Verduyn, P., Lee, D. S., Park, J., Shablack, H., Orvell, A., Bayer, J., ... \& Kross, E. (2015). Passive Facebook usage undermines affective well-being: Experimental and longitudinal evidence. Journal of Experimental Psychology: General, 144(2), 480.

Vondráčková, P., \& Gabrhelik, R. (2016). Prevention of Internet addiction: A systematic review. Journal of behavioral addictions, 5(4), 568-579.

Walther, B., Hanewinkel, R., \& Morgenstern, M. (2014). Effects of a brief school-based media 
literacy intervention on digital media use in adolescents: Cluster randomized controlled trial. Cyberpsychology, Behavior, and Social Networking, 17(9), 616-623.

Wang, J. L., Jackson, L. A., Gaskin, J., \& Wang, H. Z. (2014). The effects of Social Networking Site (SNS) use on college students' friendship and well-being. Computers in Human Behavior, 37, 229-236.

Wenninger, H., Krasnova, H., \& Buxmann, P. (2019). Understanding the role of social networking sites in the subjective well-being of users: a diary study. European Journal of Information Systems, 28(2), 126-148.

Yu, L., \& Shek, D. T. L. (2013). Internet addiction in Hong Kong adolescents: a three-year longitudinal study. Journal of pediatric and adolescent gynecology, 26(3), S10-S17.

Zimmermann, L. (2020). An App to Control App Usage: Does Screen Time Tracking Affect User Behavior?. In Academy of Management Proceedings (Vol. 2020, No. 1, p. 14848). Briarcliff Manor, NY 10510: Academy of Management. https://doi.org/10.5465/AMBPP.2020.14848abstract 
Figure 1 - Flow diagram of the cluster randomised trial (number of students and classes)

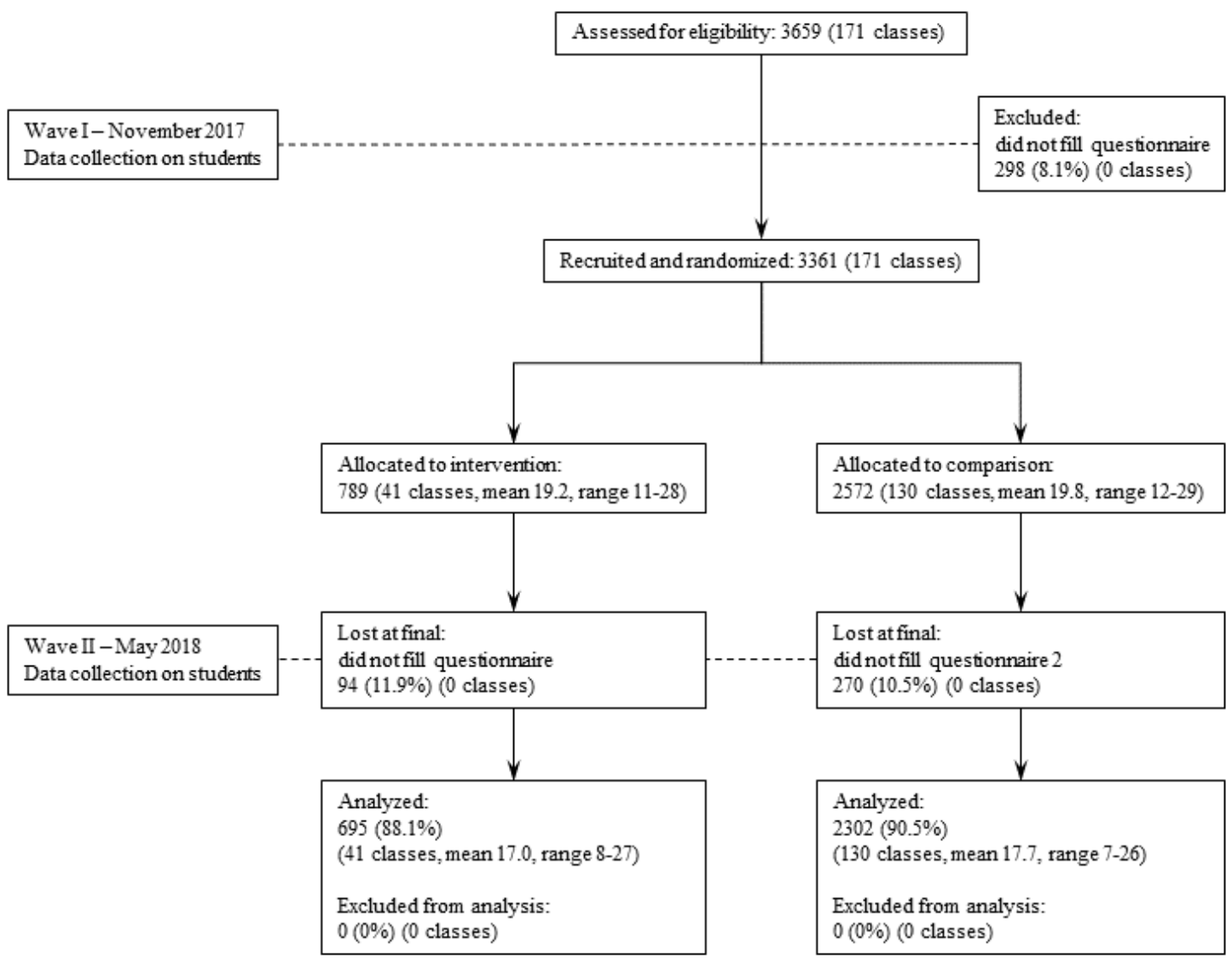


Table 1 - Effects of the intervention on the outcomes measured at the student level: predicted average scores of by experimental group, adjusted OLS model estimates and

\begin{tabular}{lcccc}
\multicolumn{4}{c}{ effect size } & \\
& \multicolumn{2}{c}{$\begin{array}{c}\text { Predicted average } \\
\text { score }\end{array}$} & $\begin{array}{c}\text { Main } \\
\text { effect }\end{array}$ & Effect size \\
& Controls & Treated & & \\
& 41.6 & 68.1 & $26.5^{* * *}$ & 0.873 \\
Perceived teacher support & $(0.8)$ & $(1.5)$ & $(1.7)$ & {$[0.785 ; 0.960]$} \\
Time management & & & & \\
Smartphone pervasiveness & 42.5 & 40.0 & $-2.6^{* * *}$ & -0.183 \\
& $(0.4)$ & $(0.7)$ & $(0.8)$ & {$[-0.268 ;-0.098]$} \\
Disturbance of adaptive functions & 36.2 & 34.2 & $-2.0^{* *}$ & -0.117 \\
& $(0.4)$ & $(0.6)$ & $(0.7)$ & {$[-0.202 ;-0.032]$} \\
Withdrawal & 28.5 & 27.3 & -1.3 & -0.075 \\
Content management & $(0.4)$ & $(0.7)$ & $(0.8)$ & {$[-0.160 ; 0.010]$} \\
Digital competence test & & & & \\
Tangible outcomes of internet use & $(0.4)$ & $(0.7)$ & $(0.8)$ & {$[-0.148 ; 0.022]$} \\
& $(0.8$ & 51.2 & 0.4 & 0.035 \\
Creative media use & 11.1 & 11.2 & 0.1 & 0.058 \\
& $(0.8)$ & $(0.9)$ & $(1.2)$ & {$[-0.027 ; 0.143]$} \\
Active social media use & 30.5 & 28.8 & -1.7 & -0.105 \\
& $(0.6)$ & $(0.8)$ & $(1.0)$ & {$[-0.190 ;-0.020]$}
\end{tabular}

General well-being

Satisfaction with life

$\begin{array}{llll}54.6 & 55.0 & 0.4 & 0.037\end{array}$

$(0.3) \quad(0.6) \quad(0.7) \quad[-0.048 ; 0.122]$

Notes: standard errors clustered at class level in round parentheses. 95\% confidence intervals in square parentheses. $* * * \mathrm{p} \leq 0.001, * * \mathrm{p} \leq 0.01, * \mathrm{p} \leq 0.05$ 
Table 2 - Differential effects of the intervention across gender. Adjusted OLS interaction model estimates and effect size

\begin{tabular}{|c|c|c|c|c|c|}
\hline & \multicolumn{2}{|r|}{ Males } & \multicolumn{2}{|c|}{ Females } & \multirow[b]{2}{*}{ Diff. } \\
\hline & $\begin{array}{c}\text { Marginal } \\
\text { effect }\end{array}$ & Effect size & $\begin{array}{c}\text { Marginal } \\
\text { effect }\end{array}$ & Effect size & \\
\hline $\begin{array}{l}\text { Perceived teacher } \\
\text { support }\end{array}$ & $\begin{array}{c}25.8 * * * \\
(2.4)\end{array}$ & $\begin{array}{c}0.815 \\
{[0.688 ; 0.941]}\end{array}$ & $\begin{array}{l}27.1 * * * \\
(2.1)\end{array}$ & $\begin{array}{c}0.938 \\
{[0.816 ; 1.061]}\end{array}$ & $\begin{array}{c}1.3 \\
(3.0)\end{array}$ \\
\hline \multicolumn{6}{|l|}{ Time management } \\
\hline Smartphone & -2.0 & -0.170 & $-3.2 * * *$ & -0.195 & -1.3 \\
\hline pervasiveness & (1.1) & {$[-0.293 ;-0.048]$} & $(0.9)$ & {$[-0.312 ;-0.077]$} & $(1.3)$ \\
\hline Disturbance of & -1.1 & -0.035 & $-2.9 * *$ & -0.188 & -1.8 \\
\hline adaptive functions & $(1.2)$ & {$[-0.158 ;-0.087]$} & $(0.9)$ & {$[-0.306 ;-0.071]$} & $(1.5)$ \\
\hline Withdrawal & $\begin{array}{c}0.9 \\
(1.1)\end{array}$ & $\begin{array}{c}0.066 \\
{[-0.056 ; 0.189]}\end{array}$ & $\begin{array}{c}-3.2 * * \\
(1.1)\end{array}$ & $\begin{array}{c}-0.191 \\
{[-0.309 ;-0.073]}\end{array}$ & $\begin{array}{r}-4.1^{*} \\
(1.6)\end{array}$ \\
\hline \multicolumn{6}{|l|}{$\begin{array}{l}\text { Content } \\
\text { management }\end{array}$} \\
\hline $\begin{array}{l}\text { Digital } \\
\text { competence test }\end{array}$ & $\begin{array}{l}-0.3 \\
(0.8)\end{array}$ & $\begin{array}{c}0.026 \\
{[-0.096 ; 0.149]}\end{array}$ & $\begin{array}{l}1.0^{*} \\
(0.5)\end{array}$ & $\begin{array}{c}0.045 \\
{[-0.073 ; 0.163]}\end{array}$ & $\begin{array}{l}1.3 \\
(0.9)\end{array}$ \\
\hline $\begin{array}{l}\quad \text { Tangible } \\
\text { outcomes of } \\
\text { internet use }\end{array}$ & $\begin{array}{l}-0.7 \\
(1.2)\end{array}$ & $\begin{array}{c}-0.007 \\
{[-0.129 ; 0.116]}\end{array}$ & $\begin{array}{l}-2.0 \\
(1.1)\end{array}$ & $\begin{array}{c}-0.133 \\
{[-0.250 ;-0.015]}\end{array}$ & $\begin{array}{l}-1.3 \\
(1.7)\end{array}$ \\
\hline Creative media & 1.6 & 0.010 & -1.2 & -0.113 & -2.8 \\
\hline use & (1.6) & {$[-0.113 ; 0.132]$} & (1.1) & {$[-0.230 ; 0.005]$} & $(1.5)$ \\
\hline Active social & -2.3 & -0.158 & -1.2 & -0.047 & 1.1 \\
\hline media use & (1.3) & {$[-0.280 ;-0.035]$} & (1.1) & {$[-0.164 ; 0.071]$} & (1.4) \\
\hline \multicolumn{6}{|l|}{ General well-being } \\
\hline Satisfaction & -1.1 & -0.060 & $1.8^{*}$ & 0.123 & $2.9 *$ \\
\hline with life & $(1.1)$ & {$[-0.183 ; 0.063]$} & $(0.8)$ & {$[0.005 ; 0.241]$} & $(1.5)$ \\
\hline
\end{tabular}

Table 3 - Gender differences in the distribution of baseline outcomes

\begin{tabular}{|c|c|c|c|}
\hline & Males & Females & P-value \\
\hline Perceived teacher support & $39.3(31.6)$ & $41.1(28.3)$ & 0.075 \\
\hline \multicolumn{4}{|l|}{ Time management } \\
\hline Smartphone pervasiveness & $42.9(20.2)$ & $45.5(19.2)$ & 0.000 \\
\hline $\begin{array}{l}\text { Disturbance of adaptive } \\
\text { functions }\end{array}$ & $37.2(22.2)$ & $40.3(23.8)$ & 0.000 \\
\hline Withdrawal & $28.0(21.5)$ & $36.0(24.0)$ & 0.000 \\
\hline \multicolumn{4}{|l|}{ Content management } \\
\hline Digital competence test & $48.2(12.4)$ & $47.6(9.6)$ & 0.092 \\
\hline $\begin{array}{l}\text { Tangible outcomes of } \\
\text { internet use }\end{array}$ & $63.7(22.5)$ & $64.7(20.6)$ & 0.199 \\
\hline Creative media use & $9.8(20.1)$ & $12.4(26.4)$ & 0.002 \\
\hline Active social media use & $27.8(21.5)$ & $33.5(21.4)$ & 0.000 \\
\hline \multicolumn{4}{|l|}{ General well-being } \\
\hline Satisfaction with life & $57.3(21.2)$ & $51.4(21.1)$ & 0.000 \\
\hline
\end{tabular}

Notes: standard deviations in round parentheses. 


\section{Supplementary Material 1 (SM1) - Outcome Content and Properties}

\section{Digital Competence Test}

The Bicocca-Fastweb Digital Competence Test consists of 32 multiple-choice items based on realistic internet stimuli (screenshots, situations etc.) aimed at quantifying the level of awareness respondents have in searching for and producing online information, in communicating on digital platforms and in managing their online identity (for a practical example of item formulation, see Authors, 2018). It was developed and validated by a group of experts from different disciplines, in accordance with the guidelines provided in the DigComp 2.1 European framework, and taking into account the age range of the target population. The preliminary version of the test was pre-tested and revised one year before the trial on a sample of 125 grade-10 students. It was then administered and validated in the first wave of data collection of the Digital Well-being - School project (see Gui et al., 2018).

The unidimensionality of the digital competence latent construct was confirmed by the results of a bi-factor analysis, showing that over $76 \%$ of the common variance between the items included in the test was explained by a single latent factor. This one-factor solution fitted the data properly, and also proved to have a sufficient degree of internal reliability $($ KR20 $=$ 0.740). The factorial validity of the test was finally evaluated with a confirmatory factor analysis, estimating a single factor model with a robust weighted least square estimation method (WLSMV) to deal with dichotomous variables (Asparouhov \& Muthén, 2010). According to $\mathrm{Hu}$ and Bentler (1999), we obtained satisfactory results in the interpretation of the alternative fit indices $(\chi 2=1,174, \mathrm{df}=464, \mathrm{p}<.001$; RMSEA $=.021[.020, .023]$; CFI $=$ $.939 ; \mathrm{TLI}=.935)$ thus confirming the factorial validity of the test.

\section{Scales of perceived teacher support, time management, content management and general well-being}

The perceived teacher support scale consists of an ad hoc battery of categorical items we developed to quantify students' exposure to the course contents, while smartphone pervasiveness and problematic uses, capital-enhancing digital media uses and general wellbeing were measured using batteries of ordered categorical items derived from previous 
literature. The descriptive statistics for the items of all these scales measured at wave 1 are reported in table 1.

Table 1 -Descriptive statistics of the items measured at wave 1

\begin{tabular}{|c|c|c|c|c|c|}
\hline Scale/Items & $\mathbf{M}$ & SD & Mdn & Q1 & Q \\
\hline \multicolumn{6}{|l|}{ Perceived teacher support } \\
\hline \multicolumn{6}{|l|}{ Since the beginning of this school year, your teachers... (0 "No" and 1 "yes") } \\
\hline helped you judge the reliability of information you found on the internet & 0.472 & & & & \\
\hline have suggested how to behave on social networks & 0.521 & & & & \\
\hline have discussed with you how to manage privacy in social networks & 0.434 & & & & \\
\hline Suggested you how to create and publish online contents & 0.262 & & & & \\
\hline have discussed with you the dangers of excessive internet use & 0.616 & & & & \\
\hline they advised you on how to better manage your time online & 0.313 & & & & \\
\hline $\begin{array}{l}\text { they suggested how to manage your smartphone at home with your } \\
\text { family }\end{array}$ & 0.199 & & & & \\
\hline \multicolumn{6}{|l|}{ Smartphone pervasiveness (Authors) } \\
\hline \multicolumn{6}{|c|}{ How often do you use your smartphone during the following daily situations? (From 1 "Never" to 4 "Always") } \\
\hline At dinner with your family & 1.719 & 0.885 & 1 & 1 & 2 \\
\hline while you are spending time with your friends & 2.668 & 0.760 & 3 & 2 & 3 \\
\hline while you are studying & 2.644 & 0.832 & 3 & 2 & 3 \\
\hline during the night, if you wake up & 1.904 & 1.128 & 1 & 1 & 3 \\
\hline First thing in the morning, when you wake up & 2.701 & 1.125 & 2 & 3 & 4 \\
\hline At school, during the lessons & 2.174 & 0.963 & 2 & 1 & 3 \\
\hline While you are watching a movie or a TV show & 2.481 & 0.904 & 2 & 2 & \\
\hline
\end{tabular}

Disturbance of adaptive functions (Kim et al. 2014; Kwon et al. 2013)

How much do you agree with the following statements? (From 1 "Strongly disagree" to 6 "Strongly agree")

My school performances dropped due to excessive smartphone use $\quad \begin{array}{lll}2.752 & 1.559 & 3\end{array}$

I have hard time concentrating on studying due to smartphone use

I happen to miss my planned work due to smartphone use

$1-4$

I frequently argue with my family because of the time I spend on my smartphone

The people around me tell me that I use the smartphone too much

$\begin{array}{lllll}3.047 & 1.540 & 3 & 2 & 4\end{array}$

$\begin{array}{lllll}2.653 & 1.569 & 2 & 1 & 4\end{array}$

$\begin{array}{lllll}3.284 & 1.659 & 3 & 2 & 5\end{array}$

$2.961 \quad 1.506 \quad 3 \quad 2 \quad 4$

Smartphone withdrawal (Kim et al. 2014; Kwon et al. 2013)

How much do you agree with the following statements? (From 1 "Strongly disagree" to 6 "Strongly agree")

When I cannot use a smartphone, I feel alone and useless

I feel impatient and fretful when I am not holding my smartphone

$\begin{array}{lll}2.348 & 1.467 & 2 \\ 2,293 & 1.462 & 2 \\ 2.998 & 1.666 & 3 \\ 2.203 & 1.415 & 2 \\ 3,200 & 1.598 & 3\end{array}$

I panic when I cannot use my smartphone

I have my smartphone in my mind even when I am not using it

I won't be able to stand not having my smartphone

$3,200 \quad 1.598$

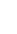
(1) (3)

Tangible outcomes of Internet use (Helsper et al. 2015)

How much do you agree with the following statements? (From 1 "Strongly disagree" to 5 "Strongly agree")

I found useful information on the internet $\quad 3.543 \quad 1.169 \quad 4$

Using the internet has helped me form opinions on complex problems

that I didn't understand well before

I learned something new by searching on the internet

I learned new things about cultures on the internet

$\begin{array}{lllll}3.443 & 1.117 & 4 & 3 & 4 \\ 3.954 & 1.016 & 4 & 4 & 5 \\ 3.339 & 1.275 & 3 & 4 & 4\end{array}$

Creative use of digital media (Ekström \& Östman 2015)

how often do you do the following online activities? (From 1 "Never" to 6 "Many times a day")

Write online texts on topics you know well

Create videos or music and upload them online

Manage your own personal web page, website or blog 


\begin{tabular}{|c|c|c|c|c|c|}
\hline \multicolumn{6}{|c|}{ how often do you do the following social media activities? (From 1 "Never" to 6 "Many times a day") } \\
\hline Comments your friends' posts & 3.189 & 1.490 & 3 & 2 & 4 \\
\hline Write your own post or upload your own content & 2.687 & 1.239 & 2 & 2 & 3 \\
\hline Share newspaper or blog articles & 1.749 & 1.379 & 1 & 1 & 2 \\
\hline Share posts or content from others & 2.522 & 1.689 & 2 & 1 & 3 \\
\hline \multicolumn{6}{|l|}{ Satisfaction with life (Diener et al. 1985) } \\
\hline \multicolumn{6}{|c|}{ How much do you agree with the following statements? (From 1 "Strongly disagree" to 6 "Strongly agree”) } \\
\hline In most ways my life is close to my ideal & 3.502 & 1.321 & 4 & 3 & 4 \\
\hline The conditions of my life are excellent & 4.147 & 1.233 & 4 & 4 & 5 \\
\hline I am satisfied with my life & 4.067 & 1.250 & 4 & 4 & 5 \\
\hline So far I have got the important things I want in life & 3.408 & 1.332 & 4 & 3 & 4 \\
\hline If I could live my life over, I would change almost nothing & 3.442 & 1.640 & 4 & 2 & 5 \\
\hline
\end{tabular}

Perceived teacher support was simply measured by the sum of the scores obtained on each item, and the resulting additive index was used to evaluate students' degree of exposure to the contents of the media education intervention.

The suitability, dimensionality and internal consistency of the outcomes related to smartphone management (i.e., smartphone pervasiveness, disturbance of adaptive functions, withdrawal), online content management (i.e., tangible outcomes of internet use, creative media use, active social media use) and general well-being (i.e., satisfaction with life) were instead evaluated on the first wave of data collected on students. Data suitability was assessed looking at the determinant of the correlation matrix (Det), the Kaiser-Meyer-Olkin measure of sampling adequacy (KMO) and the Bartlett's test of sphericity. The dimensionality of the constructs was investigated with a principal component approach, using the Horn parallel analysis with 5,000 iterations, while their internal reliability was tested with Cronbach's alpha. A summary of the results is reported in Table 1, showing a sufficient degree of data suitability for factor analysis, dimensionality and internal consistency for all the outcomes under study.

Table 2 - Results of the data suitability, dimensionality and internal consistency tests

\begin{tabular}{|c|c|c|c|c|c|c|c|c|c|}
\hline & \multirow[b]{2}{*}{ Det } & \multirow[b]{2}{*}{ KMO } & \multicolumn{3}{|c|}{ Bartlett test of sphericity } & \multicolumn{3}{|c|}{ PCA Horn parallel analysis } & \multirow[b]{2}{*}{$\begin{array}{l}\text { Cronbac } \\
\text { h alpha }\end{array}$} \\
\hline & & & $\chi^{2}$ & df & p-value & $\mathrm{N}$ & $\begin{array}{l}\text { Adjusted } \\
\text { eigenvalue }\end{array}$ & $\begin{array}{l}\% \text { Expl. } \\
\text { variance }\end{array}$ & \\
\hline \multicolumn{10}{|l|}{ Time management } \\
\hline Smartphone pervasiveness & 0.312 & 0.805 & 3898.7 & 21 & 0.000 & 1 & 2.672 & 40.0 & 0.735 \\
\hline $\begin{array}{l}\text { Disturbance of adaptive } \\
\text { functions }\end{array}$ & 0.207 & 0.738 & 5268.1 & 10 & 0.000 & 1 & 2.680 & 54.3 & 0.789 \\
\hline Withdrawal & 0.195 & 0.835 & 5477.0 & 10 & 0.000 & 1 & 2.833 & 58.3 & 0.817 \\
\hline \multicolumn{10}{|l|}{ Content management } \\
\hline Outcomes of internet use & 0.409 & 0.759 & 2937.6 & 6 & 0.000 & 1 & 2.255 & 57.1 & 0.739 \\
\hline Creative media use & 0.326 & 0.709 & 3758.4 & 3 & 0.000 & 1 & 2.188 & 74.1 & 0.822 \\
\hline Active social media use & 0.415 & 0.700 & 2948.6 & 6 & 0.000 & 1 & 2.197 & 55.8 & 0.725 \\
\hline \multicolumn{10}{|l|}{ General well-being } \\
\hline Satisfaction with life & 0.133 & 0.855 & 6734.5 & 10 & 0.000 & 1 & 3.073 & 62.5 & 0.840 \\
\hline
\end{tabular}

We also evaluated the factorial validity of the constructs in a confirmatory framework, using a robust maximum likelihood estimation method (MLR) to correct for non-normality in the 
distribution of the items (Satorra \& Bentler, 1994). A first-time management-related model was specified, including smartphone pervasiveness, disturbance of adaptive functions and withdrawal as three distinct but related constructs. According to the rules of thumb for the interpretation of alternative fit indices (Hu and Bentler 1999), this three-factor solution fitted the data properly $(\chi 2=924, \mathrm{df}=101, \mathrm{p}<.001 ; \mathrm{RMSEA}=.049[.046, .052]$; CFI $=.934$; TLI $=.921)$. In a second model specification, focused on content management-related constructs, we included outcomes of internet use, creative media use and active social media use as distinct but related constructs. In this case, the model exhibited a satisfactory fit to the data $(\chi 2=320$, $\mathrm{df}=40, \mathrm{p}<.001 ; \mathrm{RMSEA}=.046[.042, .051] ; \mathrm{CFI}=.967 ; \mathrm{TLI}=.955)$ and it was possible to covary the residuals of two interactive use of social media items ("Comments your friends' posts" and "Write your own post or upload your own content", respectively). Finally, we evaluated the factorial validity of the satisfaction with life scale in a single-factor specification, obtaining more than satisfactory results $(\chi 2=30, \mathrm{df}=5, \mathrm{p}<.001 ; \mathrm{RMSEA}=.038[.026, .052]$; $\mathrm{CFI}=.994 ; \mathrm{TLI}=.989)$.

\section{References}

Gui, M., Gerosa, T., Garavaglia, A., Petti, L., \& Fasoli, M. (2018). Digital well-being. Validation of a digital media education programme in high schools. Report, Research Center on Quality of Life in the Digital Society, University of Milano-Bicocca, Italy, November.

Asparouhov, T., \& Muthén, B. (2010). Weighted least squares estimation with missing data [Mplus technical appendix]. Retrieved from https://www.statmodel.com/download/GstrucMissingRevision.pdf

Diener, E. D., Emmons, R. A., Larsen, R. J., \& Griffin, S. (1985). The satisfaction with life scale. Journal of personality assessment, 49(1), 71-75.

Ekström, M., \& Östman, J. (2015). Information, interaction, and creative production: The effects of three forms of internet use on youth democratic engagement. Communication Research, 42(6), 796-818.

Escobar-Viera, C. G., Shensa, A., Bowman, N. D., Sidani, J. E., Knight, J., James, A. E., \& Primack, B. A. (2018). Passive and active social media use and depressive symptoms among United States adults. Cyberpsychology, Behavior, and Social Networking, 21(7), 437-443.

Helsper, E. J., Van Deursen, A. J., \& Eynon, R. (2015). Tangible outcomes of Internet use: from digital skills to tangible outcomes project report.

Hu, L., \& Bentler, P. M. (1999). Cutoff criteria for fit indexes in covariance structure analysis: Conventional criteria versus new alternatives. Structural Equation Modeling: A Multidisciplinary Journal, 6(1), 1-55. doi:10.1080/10705519909540118

Kim, D., Lee, Y., Lee, J., Nam, J. K., \& Chung, Y. (2014). Development of Korean smartphone addiction proneness scale for youth. PloS one, 9(5), e97920. 
https://doi.org/10.1371/journal.pone.0097920

Kwon, M., Lee, J. Y., Won, W. Y., Park, J. W., Min, J. A., Hahn, C., ... \& Kim, D. J. (2013). Development and validation of a smartphone addiction scale (SAS). PloS one, 8(2), e56936.

Satorra, A., \& Bentler, P. M. (1994). Corrections to test statistics and standard errors in covariance structure analysis. In Latent variables analysis: Applications for developmental research (pp. 399-419). Sage Publications, Inc. 


\section{Supplementary Material 2 (SM2) - Internal Validity of the Experiment}

In the following pages, we report evidence proving that the key threats to the experiment's (internal) validity were properly managed in our study.

\section{Equivalence}

As displayed in table 3, control and treatment groups were equivalent, both at students and class level, looking at a wide set of socio-demographic characteristics.

Table 3 -Equivalence between control and treatment groups on covariates measured before the intervention

\begin{tabular}{|c|c|c|c|c|c|c|}
\hline & \multicolumn{4}{|c|}{ Individual level } & \multicolumn{2}{|c|}{ Class level } \\
\hline & \multicolumn{2}{|c|}{$\begin{array}{l}\text { Controls } \\
(\mathrm{n}=2.572)\end{array}$} & \multicolumn{2}{|c|}{$\begin{array}{l}\text { Treated } \\
(\mathrm{n}=789)\end{array}$} & \multirow{2}{*}{$\begin{array}{l}\text { Controls } \\
(\mathrm{n}=130) \\
\mathrm{M}(\mathrm{SD})\end{array}$} & \multirow{2}{*}{$\begin{array}{c}\begin{array}{c}\text { Treated } \\
(\mathrm{n}=41)\end{array} \\
\mathrm{M}(\mathrm{SD})\end{array}$} \\
\hline & $\mathrm{M}(\mathrm{SD})$ & $\%$ & $\mathrm{M}(\mathrm{SD})$ & $\%$ & & \\
\hline \multicolumn{7}{|l|}{ Socio-demographic: } \\
\hline Female & & 51.8 & & 51.5 & $51.7(28.7)$ & $51.0(29.4)$ \\
\hline missing & & - & & - & - & - \\
\hline Migrant (1st and 2nd gen.) & & 12.9 & & 12.4 & $13.5(11.9)$ & $12.9(12.7)$ \\
\hline missing & & 0.6 & & 0.4 & - & - \\
\hline Age of respondent in years & $\begin{array}{l}15.2 \\
(0.6)\end{array}$ & & $15.2(0.6)$ & & $15.2(0.2)$ & $15.2(0.3)$ \\
\hline missing & & - & & - & - & - \\
\hline \multicolumn{7}{|l|}{ Family educational level } \\
\hline Low (up to lower secondary) & & 10.0 & & 10.7 & $11.7(9.6)$ & $12.8(12.0)$ \\
\hline Middle (upper secondary) & & 44.2 & & 40.7 & $48.7(14.2)$ & $45.5(15.2)$ \\
\hline High (tertiary) & & 37.9 & & 41.7 & $39.6(17.2)$ & $41.7(17.9)$ \\
\hline missing & & 7.9 & & 7.0 & - & - \\
\hline \multicolumn{7}{|l|}{ Internet and smartphone: } \\
\hline Internet connection at home & & 97.3 & & 98.0 & $97.2(4.4)$ & $98.0(2.9)$ \\
\hline missing & & 0.1 & & - & - & - \\
\hline Smartphone ownership & & 98.4 & & 98.9 & $98.4(3.6)$ & $99.0(2.0)$ \\
\hline missing & & 0.1 & & - & - & - \\
\hline Age access smartphone & $\begin{array}{l}11.3 \\
(1.5)\end{array}$ & & $11.3(1.5)$ & & $11.3(0.4)$ & $11.3(0.4)$ \\
\hline missing & & 1.6 & & 1.1 & - & - \\
\hline Mobile internet connection & & 92.1 & & 91.4 & $93.4(6.4)$ & $92.0(8.2)$ \\
\hline Missing & & 1.6 & & 1.3 & - & - \\
\hline Parenting style: limit internet & & 44.7 & & 45.3 & $44.5(14.0)$ & $45.1(9.9)$ \\
\hline \multicolumn{7}{|l|}{ use } \\
\hline Missing & & 0.4 & & 0.1 & - & - \\
\hline $\begin{array}{l}\text { Parenting style: discuss } \\
\text { internet use }\end{array}$ & & 50.8 & & 49.8 & $50.9(12.5)$ & $50.5(12.3)$ \\
\hline missing & & 0.5 & & 0.3 & - & - \\
\hline \multicolumn{7}{|l|}{ Education: } \\
\hline Type of school & & 0.4 & & 0.4 & - & - \\
\hline Lyceum & & 53.1 & & 53.0 & $50.0(50.2)$ & $48.8(50.6)$ \\
\hline Technical Institute & & 33.7 & & 32.6 & $35.4(48.0)$ & $34.2(48.0)$ \\
\hline Vocational school & & 13.1 & & 14.5 & $14.6(35.5)$ & $17.1(38.1)$ \\
\hline missing & & - & & - & - & - \\
\hline Grade point average $(0-10)$ & $6.5(1.1)$ & & $6.5(1.0)$ & & $6.5(0.4)$ & $6.4(0.4)$ \\
\hline missing & & 0.7 & & 0.6 & - & - \\
\hline Rejected at least for one year & & 18.2 & & 17.4 & $19.7(16.3)$ & $18.2(16.2)$ \\
\hline
\end{tabular}


Similar results also emerge when looking at the distribution of the pre-intervention outcomes across the experimental groups (Table 4).

Table 4 -Equivalence between control and treatment groups on baseline outcomes

\begin{tabular}{|c|c|c|c|c|c|c|c|}
\hline \multirow[b]{2}{*}{ Perceived teacher support } & \multicolumn{2}{|c|}{ Overall sample } & \multicolumn{2}{|c|}{ Controls } & \multicolumn{2}{|c|}{ Treated } & \multirow{2}{*}{$\frac{p \text {-value }}{0.081}$} \\
\hline & 40.2 & $(30.0)$ & 39.7 & $(29.6)$ & 41.9 & $(31.1)$ & \\
\hline \multicolumn{8}{|l|}{ Time management } \\
\hline Smartphone pervasiveness & 44.2 & (19.7) & 44.4 & (19.7) & 43.8 & (19.9) & 0.457 \\
\hline Disturbance of adaptive functions & 38.2 & $(23.1)$ & 39.1 & $(23.4)$ & 37.7 & $(21.9)$ & 0.136 \\
\hline Withdrawal & 32.2 & $(23.2)$ & 32.3 & $(23.2)$ & 31.8 & $(22.9)$ & 0.589 \\
\hline \multicolumn{8}{|l|}{ Content management } \\
\hline Digital competence test & 47.9 & $(11.1)$ & 47.9 & $(11.0)$ & 47.9 & $(11.1)$ & 0.997 \\
\hline Tangible outcomes of internet use & 64.1 & $(21.5)$ & 64.4 & $(21.4)$ & 63.6 & $(21.9)$ & 0.391 \\
\hline Creative media use & 11.2 & (23.6) & 11.2 & $(23.7)$ & 10.9 & $(23.3)$ & 0.720 \\
\hline Active social media use & 30.7 & $(21.6)$ & 30.6 & $(21.6)$ & 31.2 & $(21.6)$ & 0.496 \\
\hline \multicolumn{8}{|l|}{ General well-being } \\
\hline Satisfaction with life & 54.3 & $(21.3)$ & 54.0 & (21.4) & 55.0 & $(21.0)$ & 0.276 \\
\hline
\end{tabular}

Notes: standard deviations in round parentheses.

After conducting a set of paired t-test on their baseline values, we found that all of them were equally distributed across them before the intervention. Hence, randomisation worked properly in creating two equivalent groups.

\section{Compliance}

Teachers' compliance with each of the four training modules was monitored first by looking at their presence at the meetings. They were also invited to fill in an online questionnaire after each activity was implemented in class, summarising the work they had carried out and the material they had produced with their students. By cross-referencing the information on attendance with that collected from the questionnaires, we estimated the number of teachers that successfully implemented the entire programme: $89 \%$ of teachers had carried out all the activities required for each module, but considering that teachers worked in pairs or took turns to organise and implement the workshops with the students, we can conclude that about $98 \%$ of students were exposed to all the project activities. Only one of the classes assigned to the treatment did not complete the entire training programme, although it successfully completed 
the first two training modules. At the same time, none of the control group classes were treated, so we ended up with a situation close to full compliance.

\section{Contamination}

Intervention delivery at class level is not only convenient for practical considerations, it also minimises experimental contamination, the alternative of school randomisation not being feasible for our project.

To reinforce our assumption of negligible contamination, we investigated the issue by asking enrolled schools for information on how many of the trained teachers would teach in both treated and control classes. Overall, we found that $43 \%$ of them would also be working in one or more control classes, thus generating the risk of type II error. This is the reason behind our request to train teachers both to avoid sharing any of the course content with other colleagues and to avoid replicating the [anonymised] media education activities in other classes beyond the treatment for the entire school year.

Moreover, at the end of the intervention, we looked at variations in the distribution of the perceived teacher support on a digital media scale to evaluate students' (potential) exposure to the course contents. We detected a modest increase for control group students over the year $(\mathrm{w} 1=40.1[38.9 ; 41.3] ; \mathrm{w} 2=41.5[40.2 ; 42.8] ; \mathrm{p}=.037)$, but this is negligible compared to the increase in teacher support reported by treated students $(\mathrm{w} 1=41.9[39.6 ; 44.2]$; w2 $=68.5[66.4$; 70.5]; $\mathrm{p}<.001$ ). In the light of that, there may have been a (very) moderate contamination of control students, but only under the assumption of the temporal stability of teachers' support practices in the use of digital media. However, the control group's exposure to the intervention is minimal once compared to the one of the experimental group. Hence, we can reasonably exclude significant threats to the internal validity of the experiment due to contamination.

\section{Attrition}

In the first wave of data collection, the test and questionnaire were administered to a total of 3,361 students, achieving a response rate of $92 \%$ (see Figure 1). On this occasion, missing respondents were almost entirely students absent on the dates of the survey (and any rescheduling dates, due to budget constraints). The second wave of data collection registered a loss of $11 \%$ students compared with the first wave and a total loss of $18 \%$ compared with the targeted population. This drop can be attributed in part to students being withdrawn from schools or giving up their course, and in part to the higher number of absences that tend to characterise the end of the school year. However, no signs of differential attrition were found 
across the experimental groups, with losses ranging from $12 \%$ of those allocated to the intervention to $11 \%$ for the control group. In addition, in this case, we may consider the internal validity of the experiment has been preserved. 